\title{
Rigid Spine Syndrome: A Radiologic and Manometric Study of the Pharynx and Esophagus
}

\author{
Joerg-Patrick Stübgen ${ }^{1,2}$
}

(1) Department of Neurology, University of Pretoria, Pretoria, South Africa

(2) Department of Neurology and Neuroscience, Weill Medical College of Cornell University, 525 East 68th Street, New York, New York 10021, USA

\author{
Joerg-Patrick Stübgen \\ Email: pstuebge@med.cornell.edu
}

\section{Abstract}

The rigid spine syndrome (RSS) is not a recognized cause of dysphagia. The "vacuolar variant" of RSS causes mild, generalized, and slowly progressive weakness. Respiratory evaluation detected severe restrictive chest wall defect and significant respiratory muscle weakness. We identified nine patients at our Neuromuscular Clinic over a period of years. The aim of this evaluation was to ascertain whether pharyngoesophageal dysfunction caused cough (2/9), intermittent oropharyngeal dysphagia (4/9), and aspiration pneumonia (3/9). Pharyngeal and esophageal functions were evaluated separately by conventional cineradiography and intraluminal esophageal manometry over a one-year study period. An age- and gender-matched volunteer group without swallowing complaints partook in the manometric component of the study. There were seven male and two female patients. The mean age of patients was 19.1 years (17.8 years for controls), and the age range was 11-36 years (13-32 years for controls). The mean disease duration was 17.2 years (range $=8-31$ years). Patients were commonly underweight (7/9). Cineradiology detected abnormal swallow physiology of pharyngeal striated muscle (1/9) and of esophageal smooth muscle (2/9). Mean manometric pressures in patients were not significantly different from control data. Manometry detected "nonspecific" contractility abnormalities (3/9) that were not reflected in the mean data. The relative lack of instrumental findings suggested minor upper alimentary tract dysmotility in patients with the RSS. The myopathy that underlies this syndrome likely caused dysfunction of the striated muscle of the pharyngeal constrictors and upper esophageal sphincter. The documented abnormalities of esophageal smooth muscle motility were nonspecific and tenuously associated with the muscle disorder. The incongruity between complaints of intermittent dysphagia and study results was perhaps due to transient pharyngoesophageal dysmotility, altered swallowing mechanics of limited cervical spine mobility, altered swallowing perception after previous intubation/tracheostomy, or a "functional" upper intestinal complaint. Joerg-Patrick Stübgen MD 
Muscle disorders known to cause motor (neuromuscular) dysphagia include the inflammatory myopathies [1], myotonic dystrophy [2], oculopharyngeal myopathy [3], and limb girdle muscular dystrophy (LGMD) [4]. Myotonic dystrophy affects the esophageal smooth muscle with consequent weak contractions and paralysis of the esophageal body [2]. Patients with LGMD suffer with nonspecific pharyngoesophageal motility disorders [4]. Disorders of deglutition are probably underrecognized in patients with muscle disease. Patients without complaints referable to deglutition are not evaluated routinely for a swallowing disorder. Therefore, subclinical swallowing problems may be overlooked. Alternatively, normal pharyngeal or esophageal studies are less likely to be reported. We identified a group of patients with rigid spine syndrome (RSS), some of whom complained of oropharyngeal dysphagia. There is no information available whether the diverse myopathies that cause the RSS involve pharyngeal striated or esophageal smooth muscles.

RSS is a group of childhood-onset muscle disorders characterized by marked limitation of flexion of the spine; contractures of limb joints, especially the elbows; mild and nonprogressive proximal weakness; a progressive scoliosis; moderately elevated muscle enzymes; a "myopathic" electromyogram pattern in spinal muscles; and histologic features of a nonspecific myopathy, often with marked fibrosis [5-9]. Doubts have been expressed about whether RSS is a single nosologic entity because the hereditary patterns, degree and distribution of weakness, cardiac involvement, and the muscle histology vary considerably in the reported cases $[10,11]$.

We reported on the phenotype of a homogeneous group of patients with the "vacuolar variant" of RSS [12]. Patients suffered slowly progressive, generalized, mild weakness. All skeletal muscle biopsies showed characteristic, though not unique, histology findings that included autophagic vacuoles, vacuoles containing capillaries, muscle spindle swelling, and type 1 fiber predominance.

This "vacuolar" myopathy affected not only limb muscles. Subsequent respiratory evaluation of patients demonstrated a severe restrictive chest wall defect and clinically significant respiratory muscle weakness that led to hypercapnic ventilatory failure in some patients [13]. Acute respiratory failure that required assisted ventilation developed in some patients and was triggered by bouts of bronchopneumonia. We undertook a study of pharyngeal and esophageal functions to determine (1) the pathophysiology of any swallowing complaints, (2) whether bouts of cough or bronchopneumonia were caused by aspiration, and (3) whether this apparently unique myopathy affected muscles of deglutition.

\section{Methods}

Nine patients that fit the phenotype description of RSS were identified over the course of years at the Neuromuscular Clinic (a tertiary referral center) of the University of Pretoria, 
South Africa [12]. The study included seven males and two females of South African Afrikaner descent, ranging in age when examined from 11 to 36 years. There was no parental consanguinity but two siblings in two families were affected. Recognized disease onset was before six years of age in all patients and likely since birth in five patients diagnosed with infantile hypotonia. The characteristic skeletal muscle histologic features included autophagic vacuoles, vacuoles containing capillaries, muscle spindle swelling, and type 1 muscle fiber predominance ( 8 of 9 patients biopsied; biopsy not performed on an affected sibling).

Patients were questioned about symptoms relating to the upper gastrointestinal tract, e.g., dysphagia for liquids and solids, aspiration, cough, regurgitation, or dyspepsia. For esophageal manometry age- and gender-matched volunteers or existing data were chosen as controls. Neither patients nor controls used medication that interfered with the function of the esophageal smooth muscle or the autonomic nervous system. All nine patients agreed to enrollment in the study. Patients or parents gave written consent to partake in the tests.

To determine the overall weight classification of patients, body mass index (BMI) was calculated as $M / H^{2}\left(\mathrm{~kg} / \mathrm{m}^{2}\right)$, where $M$ is body mass and $H$ is height. A BMI of 19-24.9 $\mathrm{kg} / \mathrm{m}^{2}$ was considered normal, $15-18.9 \mathrm{~kg} / \mathrm{m}^{2}$ underweight, and less than $15 \mathrm{~kg} / \mathrm{m}^{2}$ indicated emaciation [14].

\section{Manual Muscle Testing}

To assess muscle strength manually, a modification of the British Medical Research Council (MRC) scale was chosen [15]. Quantification of global muscle strength was obtained by testing movements around the neck, shoulders, elbows, wrists, hips, knees and ankles; 17 muscle groups on both sides were examined. For the purpose of analysis, the MRC scale was converted to a $1-10$ point system: $0=0 ; 2=2 ; 3-=3 ; 3=4 ; 3+=5$; $4-, 4$, and $4+=7 ; 5-=9$; and $5=10$. The average muscle score (AMS) is the numerical average of 34 muscles tested. Of a possible maximum score of 10 , the lower the score, the weaker the patient.

\section{Radiologic Evaluation}

A chest roentgengram was obtained in every patient to assess for shift of the posterior mediastenum, esophageal dilatation, or active lung infection. Patients were studied by a solid-bolus barium swallow technique and cineradiography (Marconi image intensifier). They were imaged in the erect and supine positions and asked to swallow a one-third to one-half portion of standard marshmallow with diluted barium suspension (Baritop 100; $100-120 \mathrm{ml})$. The screening time was 1.5-4.0 min with a frame rate of 50/s. Particular attention was paid to the supine component of the study because in the erect position the effect of gravity may overcome radiographic evidence of weakness or dysfunction of the swallowing mechanism. The function of the pharynx, M. cricopharyngeus, and esophagus was assessed according to published criteria $[16,17]$. 


\section{Esophageal Manometry}

Conventional esophageal manometry was performed according to an established technique on all subjects in the supine position after a fasting period of longer than $6 \mathrm{~h}$. Intraluminal pressures were recorded on a low-compliance microcapillary infusion system (JS Biomedicals, Ventura, CA) [18]. A triple-lumen esophageal catheter (external diameter $=3 \mathrm{~mm}$ ) was passed via the nose. The three side ports were oriented radially at $120^{\circ}$ to one another and were $5 \mathrm{~cm}$ apart. The catheter was continuously perfused with distilled water at a rate of $0.6 \mathrm{ml} / \mathrm{min}$ using a pneumohydraulic infusion pump. The output was recorded on a 4-channel Synectics polygraph system. Lower esophageal sphincter (LES) pressure was measured at end-inspiration and end-expiration by a standard station pull-through technique (the catheter was withdrawn from the stomach at $0.5-\mathrm{cm}$ increments). Values were recorded as means of pressure readings of five pullthroughs. For esophageal body manometry, the catheter tip was positioned $5 \mathrm{~cm}$ above the upper border of the LES so that the distal, middle, and proximal ports were 5, 10, and $15 \mathrm{~cm}$ from this sphincter, respectively. Amplitude of contractions (in $\mathrm{mmHg}$ ) was measured from the esophageal baseline pressure to the peak of the complex. Contraction duration (in seconds) was measured from the intersection of lines for the mean resting intraesophageal pressure and the upstroke of the complex to its return to the mean resting pressure.

Mean values were determined from ten wet swallows ( $5 \mathrm{ml}$ of water) at 30 -s intervals. Upper esophageal sphincter (UES) pressure was measured by slight modification of the rapid pull-through technique, with breath held at midinspiration and the patient's neck was in comfortable extension $[19,20]$. Sphincter pressure was recorded in mmHg above esophageal baseline pressure. The oral end of the UES was defined as $10 \mathrm{mmHg}$ above baseline. Controversies surround the interpretation of UES pressure measurements obtained with a triple-lumen catheter $[21,22]$. Because the identical technique was used by the same investigator on all subjects, and the mean of 15 readings ( 5 pull-throughs for each of 3 orifices) per patient was used for analysis, this study was regarded acceptable to evaluate interpatient and intergroup differences. Results of pressure records for any subject were abnormal if values fell outside the group mean plus 2 SD (standard deviation) and were not adjusted for age.

\section{Statistical Analysis}

The Pearson correlation coefficient was used to (1) determine the relation between patient age and disease duration and AMS, and (2) compare the means of the esophageal manometry results in the patient group versus control group. The statistical significance of data was established at $p<0.05$. This protocol was used also in a study of patients with LGMD [4].

\section{Results}

\section{Patients}

Over the course of years nine patients ( 7 males and 2 females) were identified as having rigid spine syndrome phenotype at our Neuromuscular Clinic, a tertiary referral center 
(Table 1). The age of recognized disease onset was before six years in all patients and likely since birth in five patients diagnosed with infantile hypotonia. During the study the age of patients ranged from 11 to 36 years, and the disease duration ranged from 8 to 31 years. The AMS ranged from 9.1 to 7.9 out of 10 . There was a poor correlation between patient age or disease duration and the AMS ( $p=0.4$ for both), as expected for a clinically slow or nonprogressive myopathy. The BMI of patients varied between 12.2 and $23.1 \mathrm{~kg} / \mathrm{m}^{2}$. Six patients appeared emaciated, one patient was underweight, and two patients were deemed of "normal" weight. There was no correlation between complaints of intermittent dysphagia and BMI, so low body weight was presumed part of the RSS phenotype. Family members invariably regarded patients as "slow eaters."

Table 1 Patient information

\begin{tabular}{|c|c|c|c|c|c|c|c|c|c|c|}
\hline Pt & Age & $\begin{array}{l}\text { Disease } \\
\text { duration }\end{array}$ & AMS & BMI & Cough & Dysphagia & Pneumonia & CXR & $\begin{array}{l}\text { Radio- } \\
\text { logy }\end{array}$ & $\begin{array}{l}\text { Mano- } \\
\text { metry }\end{array}$ \\
\hline 1 & 11 & 9 & 9.1 & 12.9 & & & & decr. AP dia & & + \\
\hline 2 & 12 & 12 & 8.9 & 12.2 & & + & & & & \\
\hline 3 & 13 & 9 & 8.5 & 16.0 & & & + & scoliosis & + & + \\
\hline 4 & 13 & 8 & 8.3 & 14.5 & & + & + & & & \\
\hline 5 & 15 & 15 & 8.7 & 13.7 & & + & & scoliosis & + & \\
\hline 6 & 18 & 18 & 8.6 & 13.9 & + & & & scoliosis & & \\
\hline 7 & 23 & 23 & 7.9 & 21.1 & & & & $\begin{array}{l}\text { kyphosis; L/R } \\
\text { asym. }\end{array}$ & & \\
\hline 8 & 31 & 31 & 8.3 & 14.2 & + & & & $\begin{array}{l}\text { scoliosis ele. L } \\
\text { hemidia. decr. AP } \\
\text { dia }\end{array}$ & & \\
\hline 9 & 36 & 30 & 8.6 & 23.1 & & + & + & $\begin{array}{l}\text { scoliosis; decr. AP } \\
\text { dia }\end{array}$ & + & + \\
\hline
\end{tabular}

Age and disease duration in years; AMS out of 10; BMI in $\mathrm{kg} / \mathrm{m}^{2}$

\section{Cough}

Patients 6 and 8 suffered productive cough, though not consistently related to swallowing liquids or solids.

\section{Dysphagia}

A history of intermittent dysphagia was obtained from from patients: Patient 2 complained of problems swallowing pills, patients 4 and 9 complained of choking on liquids and larger food particles, and patient 5 complained that liquids "got stuck" in the throat.

\section{Pneumonia}

Patients 3, 4, and 9 gave a history of acute bronchopneumonia so that patients had to be temporarily mechanically ventilated. However, it was not clear that the lung infections resulted from aspiration. 


\section{Chest Roentgengrams}

X-rays showed scoliosis in five patients: Patient 7 suffered mild kyphosis; patients 3, 5, and 9 underwent corrective surgical procedures for scoliosis in mid-teenager years; patients 1,8, and 9 suffered severe anterior-posterior flattening of the chest cavity; patient 8 suffered an elevated hemidiaphragm; in patients 5 and 8 the upper lobe of a lung had a "caved in" appearance; and in Patient 7 a marked asymmetry was observed between right and left lung volumes. Control patients were not submitted to radiation exposure.

\section{Cineradiography}

In six patients the solid barium swallow and cineradiographic studies were normal, including patients 2 and 4 who complained of dysphagia and patients 6 and 8 who complained of cough.

Radiologic abnormalities were found in patient 3 who had a history of acute bronchopneumonia and in patients 5 and 9 who complained of dysphagia. Patient 3 showed "slow" (not timed) passage of barium through the pharynx, with repeated, ineffectual contractions, with minimal leakage into the vestibule of the larynx. Patient 5 showed delayed primary peristaltic contractions and reflux into the distal esophagus in the supine position due to a small sliding hernia. Patient 9 showed slowed and decreased relaxation of the proximal esophagus preceding the primary peristaltic contraction with subsequent proximal escape of barium through the UES into the hypopharynx.

\section{Esophageal Manometry}

UES, esophageal body, and LES pressures for both RSS and control groups (expressed as group means $\pm 1 \mathrm{SD}$ ) are summarized in Table 2. Group means were not significantly different when comparing patient and control data. Manometry demonstrated normal esophageal motor activity in six patients, but three patients showed abnormalities that were not reflected in the group data. Patient 1 demonstrated increased $(84 \mathrm{mmHg})$ mean peak UES pressure amplitude. Patient 3 had slowly propulsive, low-amplitude primary contractions (mean duration $=4.7 \mathrm{~s}$; mean amplitude $=28.2 \mathrm{mmHg}$ ). Patient 9 suffered "nonspecific esophageal motility disorder" characterized by simultaneous, nonperistaltic contractions of the upper and lower esophagus (3 of 10 swallows) and decreased LES end-expiratory pressure $(9.1 \mathrm{mmHg})$.

Table 2 Results of esophageal manometry

\begin{tabular}{|c|c|c|c|}
\hline & Patients & Controls & $p$ value \\
\hline \multicolumn{4}{|c|}{ Esophageal body } \\
\hline \multicolumn{4}{|c|}{ [Mean (SD) amplitude (mm Hg)] } \\
\hline Proximal (1/3) & $55(27)$ & $59(18)$ & NS \\
\hline $\operatorname{Mid}(2 / 3)$ & $62(19)$ & $64(26)$ & NS \\
\hline Distal (3/3) & $98(21)$ & $95(16)$ & NS \\
\hline \multicolumn{4}{|c|}{$[$ Mean (SD) duration (s)] } \\
\hline
\end{tabular}




\begin{tabular}{|c|c|c|c|}
\hline & Patients & Controls & $p$ value \\
\hline Proximal (1/3) & $2.9(0.9)$ & $3.2(1.7)$ & NS \\
\hline $\operatorname{Mid}(2 / 3)$ & $3.6(1.1)$ & $3.3(1.5)$ & NS \\
\hline Distal (3/3) & $3.8(0.8)$ & $3.5(0.9)$ & NS \\
\hline \multicolumn{4}{|c|}{ Lower esophageal sphincter pressure $(\mathrm{mm} \mathrm{Hg})$} \\
\hline End-expiratory & $16.1(6.4)$ & $14.9(7.6)$ & NS \\
\hline End-inspiratory & 47.9 & $45.6(8.9)$ & NS \\
\hline \multicolumn{4}{|c|}{ Upper esophageal sphincter pressure $(\mathrm{mm} \mathrm{Hg})$} \\
\hline Peak & $69.2(13.4$ & $73.1(9.9)$ & NS \\
\hline
\end{tabular}

Results expressed as means ( $\pm 1 \mathrm{SD})$

$\mathrm{NS}=$ statistically not significant

\section{Discussion}

This study reports on the only cineradiologic and manometric evaluation of pharyngoesophageal function in patients with RSS. Care was taken to select a homogeneous group of patients, because RSS is unlikely a nosologic entity with different hereditary patterns, degree and distribution of weakness, cardiac involvement, and muscle pathology $[10,11]$. In our patients every skeletal muscle biopsy showed findings such as autophagic vacuoles, vacuoles containing capillaries, muscle spindle swelling, and type 1 fiber predominance [12]. From these nonspecific biopsy findings we were unable to deduce the pathogenesis of this congenital myopathy. The benign nature of this myopathy was evident as even the oldest patients with the longest disease duration were fully functional. These patients formed a relatively large group, as the RSS literature consists mainly of case reports and small case series. No reports comment on swallowing disorders.

Evaluation of the pharynx and esophagus was undertaken to establish whether this apparently unique myopathic process that underlies RSS affected the muscles of deglutition. Such a study seemed important because we wanted to ascertain whether altered swallow physiology caused oropharyngeal dysphagia, cough, or aspiration that was complicated by bouts of acute bronchopneumonia that required temporary mechanical ventilation for acute respiratory failure. Studies were performed on all patients whether or not they suffered symptoms referable to the upper alimentary tract. Manifestations of pharyngoesophageal dysfunction were not common in this patient group; less than half the patients complained of dysphagia or demonstrated altered swallow physiology on further investigation. Because there was no close correlation between complaints of dysphagia and abnormal investigations, we concluded that it was appropriate to study by relatively noninvasive techniques even asymptomatic RSS patients to assess for a possible deglutition disorder. 
We doubted that dysphagia occurred secondary to respiratory problems, because swallowing complaints were not consistently associated with markers of respiratory disease such as cough, dyspnea, history of pneumonia, or ventilatory failure [13]. It was possible that dysphagia resulted from surgical procedures to the neck such as corrective cervicothoracic spinal fusion surgery or tracheostomy. However, there was no clear correlation between a history of such surgery and abnormal test results. No patients with productive cough suffered dysphagia or had an abnormal swallow evaluation. Therefore, any cough was probably not due to silent aspiration but due to respiratory problems.

Most of our patients were underweight, some even emaciated. There was no historic association between weight problems and complaints of dysphagia, though most patients were reported as "slow eaters." There was also no correlation between low weight problems and study abnormalities. Rather, it appeared that low body mass index was a component of the phenotype of RSS and not a reflection of the nutritional state. The RSS literature does not specifically comment on the nutritional state of patients, though it seems from photographs in case reports that they are mostly thin and asthenic.

Cineradiography and manometry are useful techniques to evaluate the pathophysiology of dysphagia in patients with neuromuscular disorders. However, in our patients the correlation was not absolute between instrumental findings and swallowing complaints. Two patients complained of dysphagia for liquids and solids and for pills, respectively, but had normal tests. Dysphagia for both liquids and solids implied a motility disorder of esophageal peristalsis or LES dysfunction rather than an obstructive cause. The intermittent nature of this complaint with normal test results suggested a transient motility disorder such as early-phase cricopharyngeal dyssynergia [23]. We suspected that difficulty swallowing only pills, without evidence of impaired transport, had a psychological basis, categorized as a "functional upper gastrointestinal complaint" [24]. We recognized that the studies represent only a very limited "snapshot" of the patients" overall swallowing ability and cannot always be relied on to be representative [25].

Our studies showed pharyngoesophageal dysfunction in four patients. Cineradiology detected abnormalities in three patients that were consistent with dysmotility of pharyngeal skeletal and esophageal smooth muscles such as ineffectual pharyngeal contractions, delayed primary esophageal peristalsis, or decreased/slowed proximal esophageal relaxation preceding primary peristalsis. Esophageal manometry detected abnormalities in three patients, including increased pressure of the UES ( $M$. cricopharyngeus), altered primary esophageal peristalsis, and decreased LES endexpiratory pressure. However, the mean manometry values were not significantly different when patients were compared with control data. The number of patients was too small to establish whether any abnormalities occurred more often in patients with RSS than in the general population. Dysfunction of the pharyngeal constrictor and cricopharyngeus skeletal muscle was probably related to "vacuolar" myopathy of RSS as these structures are recognized sites of involvement in neuromuscular disorders $[1,3]$. We lacked pathologic proof of such an association, but no other cause was established. The abnormal esophageal motility demonstrated in our patients was classified under "nonspecific motility disorders" and had a more tenuous relationship with the muscle 
disease of RSS [18]. Such findings are not pathognomonic of a myopathic disorder that affects esophageal smooth muscle because the same findings were documented in nonneuromuscular patients with upper alimentary tract complaints and, less commonly, in asymptomatic healthy volunteers [23]. These nonspecific motor abnormalities can be transient phenomena or may progress to a specific neuromuscular abnormality, e.g., esophageal aperistalsis or diffuse esophageal spasm. Therefore, follow-up studies of our patients were advised.

In summary, there was evidence of minor upper alimentary tract dysfunction in patients with the "vacuolar variant" of RSS. The myopathy that underlies this syndrome likely caused dysfunction of striated muscle of the pharyngeal constrictors and UES. Any documented esophageal dysmotility was nonspecific and had a more tenuous association with this muscle disorder. Factors that might have contributed to dysphagia were surgical procedures to the cervical spine and neck or a "functional upper gastrointestinal disorder."

\section{References}

1. Banker BQ, Engel AG. The polymyositis and dermatomyositis syndromes. In: Engel AG, Banker BQ, editors. Myology, vol 2. New York: McGraw-Hill; 1996. pp 13851422.

2. Harper PS. Myotonic Dystrophy. Philadelphia: WB Sanders; 1979.

3. Tome FMS, Fardeau M. Ocular myopathies. In: Engel AG, Banker BQ, editors. Myology, vol 2. New York: McGraw-Hill; 1986. pp 1327-1347.

4. Stübgen JP. Limb girdle muscular dystrophy: A radiologic and manometric study of the pharynx and esophagus. Dysphagia 1996;11:25-29.

5. Dubowitz V. Recent advances in neuromuscular disorders. Rheumatol Phys Med 11:126-130, 1971.

6. Dubowitz V. Rigid spine syndrome: a muscle syndrome in search of a name. Proc R Soc Med 1973;66:219-220.

7. Vogel P, Goebel HH, Seitz D. Rigid spine syndrome in a girl. J Neurol 1982;228:259-265.

8. Echenne B, Astruc J, Brunel D, Pages M, Baldet P, Martinazzo G. Congenital muscular dystrophy and rigid spine syndrome. Neuropediatrics 1983;14:97-101. 
9. Van Munster ETL, Joosten EMG, Van Munster-Uijtdehaage MAM, Kruls HJA, Terlaak HJ. The rigid spine syndrome. J Neurol Neurosurg Psychiatry 1986;49:12921297.

10. Poewe W, Willeit H, Sluga E, Mayr U. The rigid spine syndrome. A myopathy of uncertain nosologic position. J Neurol Neurosurg Psychiatry 1985;48:887-893.

11. Bertini E, Marini R, Sabetta G, Palmieri GP, Spagnoli LG, Vaccario ML, deBarsy T. The spectrum of the so-called rigid spine syndrome: nosologic considerations and report of three female cases. J Neurol 1986;223:248-253.

12. Lotz BP, Stübgen J-P. The rigid spine syndrome: a vacuolar variant. Muscle Nerve 1993;16:530-536.

13. Ras JR, van Staden M, Schultz C, Stübgen J-P, Lotz BP, van der Merwe C. Respiratory manifestations of the rigid spine syndrome. Am J Respir Crit Care Med 1994;150:540-546.

14. Llewellyn-Jones D, Abraham SF. Quetelet index in diagnosis of anorexia nervosa. $\mathrm{Br}$ Med J 1984;288:1800.

15. Mendell JR, Florence J. Manual muscle testing. Muscle Nerve 1990;13(suppl):16-20.

16. Dodds WJ. Radiology (of the esophagus and esophagogastric region). In: Margulis AR, Burhenne HJ, editors. Alimentary Tract Radiology, vol 1. St. Louis: CV Mosby; 1983. pp 529-603.

17. Seaman WB. Radiology (of the pharynx). In: Margulis AR, Burhenne HJ, editors. Alimentary Tract Radiology, vol 1. St. Louis: CV Mosby; 1983. pp 491-518.

18. Richter JE, Wu WC, Johns DN, Blackwell JN, Nelson JL, Castell JA, Castell DO. Esophageal manometry in 95 healthy volunteers. Variability of pressure with age, frequency of "abnormal" contractions. Dig Dis Sci 1987;32:583-592.

19. Dodds WJ, Hogan WJ, Stef JJ, Miller WN, Lydon SB, Andorfer RC. A rapid pullthrough technique for measuring lower oesaphageal sphincter pressure. Gastroenterology 1975;68:437-443. 
20. Welch RW, Luckman K, Ricks PM, Drake ST. Manometry of the normal upper oesophageal sphincter and its alteration in laryngectomy. J Clin Invest 1979;63:10361041.

21. Winans CS. The pharyngoesophageal closure mechanism: a manometric study. Gastroenterology 1972;63:768-777.

22. Castell JA, Castell DO. Modern solid state computerized manometry of the pharyngoesophageal segment. Dysphagia 1993;8:270-275.

23. Demeester TR, Dunnington GL. Esophageal anatomy and physiology. In: Greenfield LJ, Mulholland MW, Oldham KT, Zelenock GB, editors. Surgery: Scientific Principles and Practice. Philadelphia: JB Lippencott; 1993. pp 593-621.

24. Thompson WG, Longstreth G, Drossman DA. Functional bowel disorders, in Rome II. In: Drossman DA, Corazziari E, Talley NJ, editors. The Functional Gastrointestinal Disorders. McLean, VA: Degnon Associates; 2000. pp 355-363.

25. Wiles CM. Neurogenic dysphagia. J Neurol Neurosurg Psychiatry 1991;54:10371039. 